\title{
Re-Exploring on Japanese Values Diplomacy
}

\author{
Xu Meng \\ International Studies University of PLA \\ Nanjing 210039, China \\ E-mail: mengxu_2005@yahoo.com.cn
}

\begin{abstract}
Japan's values diplomacy was proposed by Tarou Asou Taro Aso in 2007. And in the period of Fukuda ruling, this diplomacy contemporarily withdrew from Japanese diplomatic stage, but its democratic values concept is still displayed in diplomatic activities. After Tarou Asou Taro Aso became the prime minister, what would be the position of values diplomacy in Japanese strategy and national policy? On this issue, it is necessary to have a deep exploring into Japanese values diplomacy. In this text, the author thinks that we can not just regard this kind of diplomacy as an ideological method of blocking Sino-Russian strategic space. It is more an important component of the comprehensive security cooperation strategy in the $21^{\text {st }}$ century, and it preoccupies an important status in Japanese national strategy and policy.
\end{abstract}

Keywords: Japan, Values diplomacy, Research

On January $26^{\text {th }} 2007$, in the $166^{\text {th }}$ ordinary national congress diplomatic speech, Tarou Asou Taro Aso definitely said, there were three backbones in the previous Japanese diplomacy, namely, Japan-America alliance, international coordination and focus on relationships with neighborhoods. Now another important backbone is going to be added, that is, to try to establish "Freedom and Prosperity Arc". Analyzing from a diplomatic perspective, the new diplomatic backbone proposed by Tarou Asou Taro Aso contained important national strategic meanings. It is based on democracy and peace theory after the cold war, recognizing that in order for the realization of international stabilization and prosperity, it is necessary to establish an international system based on it. Relationships among commonly liberal and democratic nations are stable, and their trust in each other is firm. It is only liberal and democratic nations that can ensure their countries' policies abide by international obligations and get others' trust. Geographically, "Freedom and Prosperity Arc" starts from North Europe, crossing through three nations of the Baltic Sea, Middle Europe, Eastern Europe, Middle Asia, Middle East, and Indian subcontinent, running through South east Asia, and finally arrives in districts of North East Asia. In "Diplomatic Book" in 2007, Japan further expanded the geographical sphere of the arc, pointing out this arc should also be commonly owned by China and Middle South America as well as Africa. It was just because Japanese government realized that geographical demarcation of this arc might lead to antipathy of nations inside and outside the arc. As the new diplomatic policy of Japan, values diplomacy has aroused obvious reactions in international society.

\section{Proposing of the background}

Values diplomacy is a general strategic implementation of Japanese diplomatic policy, not just including values of freedom and democracy, and also not just against China and Russia. For the understanding of values diplomacy, we can not just see it from a narrow viewpoint, because it also mobilizes several policy methods, such as safety guarantee, economy, economic cooperation, culture and propaganda, etc. Similar to the comprehensive safety guarantee strategy by Daping and Zhongzenggen Cabinet in the $1980 \mathrm{~s}$, it is an important part of the new strategy in the $21^{\text {st }}$ century. Therefore, its strategic target is not to adopt reforming methods in terms of diplomatic activities, but to establish diplomatic policies according to Japan's geography position after an observation of current international environment. Its final target is to realize an ordinary country status in the UN. The proposing of the values diplomacy has its era background:

\subsection{Elimination of Japan's apprehension for the surrounding Asian countries}

Japanese people believe that their country is the first one entering the age of democracy since Japan put forward freedom and democratic diplomacy. However, due to the fact that most Asian countries just broke away from colonial status after the War, there was no need for freedom and democracy. If the values diplomacy had been proposed based on 
Japanese experience, it would have encountered strong opposition of Asian countries. But after the cold war, South Korean democracy progress quickened, and China also accepted and developed the general values. All Asian countries quickened their democracy progress. Under such a circumstance, Japan thought that obstacles at proposing values diplomacy had greatly decreased.

\subsection{Decrease of Japan's apprehension for diplomatic unbalance}

Obstacles towards Japan's proposing of values diplomacy has something to do with the "Asia Disengagement Theory" of early Ming Dynasty, that is, whether Japan's diplomatic basis is from Oriental (China) or from Occidental. Although Japan lies in Asia, long-time absorption of Occidental cultural ideals has made its political and economic activities spread around the world, and its safety guarantee has to rely on America, which will be embodied in the diplomatic aspects. Therefore, how to make a balance in the Oriental and Occidental diplomacy is rather difficult. If Japan had proposed the values diplomacy too early, it would have resulted in distance sense with Asia and damage some subtle balance in diplomacy. After the cold war, multilateral diplomacy was extremely active, and the relationships between Asian and Occidental countries became more and more close, so worries about unbalance of values between Occidental and Asian countries saw its mediation. Therefore, Japan expected that its diplomacy could attain a breakthrough at this period.

\subsection{Improvement of domestic human rights and democratic establishment}

In the early period of postwar, many Japanese people thought that their freedom and democracy were forcibly implanted by America. However, it was just this kind of foreign values that made its fast growth in Japanese culture. Today, 60 years after the war, a majority of Japanese think freedom and democracy belong to their own, but not belonging to Occidental countries. This indicates that within alternation of a century, values of Japanese have already made obvious changes. Tarou Asou Taro Aso denoted "Japan brought in its freedom and democracy before the war, and again after the war, which made its citizens' attitude towards freedom and democracy just the same as that towards their proper pride." In February 2007, the Ministry of Foreign Affairs of Japan made a questionnaire on Sino-Japanese relationship, asking them "for the mutual understanding of the two countries, what should Japanese introduce to Chinese?" Most of answers were democratic human rights and pacifism, which indicated that Japanese people's understanding in freedom and democracy had achieved great changes.

\section{Strategic intension}

As an important aspect of the new comprehensive safety guarantee strategy in the $21^{\text {st }}$ century, the values diplomacy includes the following three aspects:

\section{1 melioration of Japanese image}

2.1.1 Improving its irresponsible international image in the safety guarantee field. Japanese think that in the information era, to regard values as diplomatic strategy for propaganda will achieve get twice the result with half the effort. For example, the proposing of peaceful growing positively propagandized China's peaceful theory to the world. However, the international society generally sees the economic advantages of Japan, but does not think Japan fulfills its obligations in Security Cooperation field, etc., and they think Japan just regards the Ninth Item of the Constitution as an excuse for no fulfilling its Security Cooperation obligations. In addition, as a traditional country, Japan is highly concerned in many issues, including its military affairs.

2.1.2 Changing of Japan's unprincipled diplomatic image. There have been examples about Japan's fast changing of its national policy in view of the realism and international situation. In other words, Japan's diplomacy is short of cultural conceptions, and they may give up their diplomatic image just for their interests. Furthermore, other countries at large think that the three backbones of Japan's diplomacy are mutually inconsistent, and it's hard to know exactly which one is their priority, which results in a fuzzy understanding of other countries in Japan's diplomatic policy. Therefore, it is necessary to clarify the international society's attitude towards Japan's unprincipled diplomacy.

2.1.3 The changing of its image of insufficiently developed democratic human rights. Most of the time after the War, Liberal Democratic Party was the only ruling party in Japan, and Japan continued its conservation, so it was not a real democratic country. Besides, there exists "Comfort Woman" in Japan that remains unresolved.

2.1.4 The changing of its image of never reflecting on its history. The international society, especially Asian neighbor countries think that Japan is a country which is most forgetful for its history, and which never thoroughly self-reflects and never offers an apology. At present, conservatism revives in Japan, and its motive for intentionally changes its history is more obvious, so neighboring countries' impression on this aspect goes deeper.

Considering the previous abominable image, Japan thinks that it is necessary to change it thorough its values diplomacy, which has attained its good results. According to the survey of international public opinions by BBC in the first half of 2007, among all countries that bring positive effects to the world, Japan and Canada are the first two with best results. 


\subsection{Remission of historic burden}

In the above survey by BBC, China and South Korea's judgment to Japan was the lowest. Even within more than a decade after the War, Japan could not get its neighborhood's forgiveness, and the author thinks it's a necessary reaction to Japan's diplomacy. Japanese government thinks, it is nothing the matter for China and South Korea to keep Japan in a situation of strategic defense. However, Chinese and South Korean scholars consistently hold the opinion that it is mostly due to Japan that historical issues haven't been solved from a political angle. Therefore, in the reducing of historical gap, values diplomacy provides the best resolution. Pursuing of historical truth is a freedom of academic research, and the occasion for proposing values diplomacy is rather important. At present, the international system is being re-conformed, when strengthening trust relationships may break away from the past historical burden.

\subsection{Improving of international status}

Japan believes that with the growing up of China, its international status gets continual improvement, but it is the opposite for Japan. Starting from a reasonable angle, generally a country would develop diplomacy consistent with its national power, and "a conceited diplomacy" would instead destroy its national interests. However, Japan has a tradition of over judging its power. In their eyes, a troublesome impression would do hard to their country and, most of all, it would smash its balance in its district and international society. In the changing process of international power balance, Japan should achieve a strategically mutual-benefit relationship with China, which actually means that even on a different values stand, there is also a need for the two parties to maintain and reinforce their balance relationship in the world and the district. And only if Japan strengthens its relationship with the country with which it has the same values, can Japan really improve its international status.

\section{Strategic meanings}

Since the implementation of values diplomacy, Japan's diplomacy has achieved great progress. In Asia, it has strengthened Japan's cooperative relationships with India, Australia and ASEAN; in Europe, it has strengthened Japan's strategic conversations with NATO and EU, and has enhanced its cooperative relationships with four countries of Middle East and Europe (Zech Republic, Hungary, Poland and Slovenia). All the above proves that it indeed has led to obvious reactions of the international society, and it plays a particular important part in the re-construction of international system and security cooperation field.

\subsection{Its revelation of responsibility image to the international society}

Japan considers values the most common thing. For the improvement of irresponsible impression, it definitely put its eyes on the capacious Asian and European Mainland edges, and at the same time, expresses its positive attitude of responsibility to international society. Through several times' assistance of these marginal countries to propagandize its diplomatic conception, Japan obtains affirmation from these countries. In addition, when Abe visited Europe in 2007, he denoted that Japan and NATO should bear common liabilities in the resolving of international problems. Such words were helpful in Europe's support of Japan joining the Security Council and Europe's good judgment on it in other international institutions. After the cold war, the international institution headed by UN did not play its original role. In the prevention of international system from developing towards a situation going against Japan, its values diplomacy, for sure, has played definite effects.

\subsection{Strengthening of Japanese and American Alliance}

Values diplomacy obvious displays a tendency of coming to heels with America. The fact that Japan suggested strengthening its relationship with NATO is a typical example. After the cold war, America regarded democratization promotion as a foundation for security cooperation, especially in the period of Cliton ruling, he proposed the diplomatic concept of democracy being the center. On the other hand, after the cold war, NATO kept expanding towards east, and developed activities in traditional districts with humanitarianism being an excuse. As a reaction to this tendency, Japan began to support democratization of Eastern Europe and Russia and the development of market economy. Japan's "Freedom and Prosperity Arc" is basically and geographically in conformity with the "Instable Arc" of USA in "QDR" in 2001, and happens to have the same viewpoint with continual enlarging of democracy community proposed by America in the security cooperation strategy in 2006. Therefore, Japanese and American alliance is further reinforced.

\subsection{Enlarging of Asian democratization}

One purpose of values diplomacy includes Asian democratization, while the key is to intensify its relationships with democratically large countries. In 2007 when Abe visited India, the two parties achieved a common understanding in the fact that forming strategic partnership for them was an indispensable backbone in Asian, and they played an indispensable part in the constructing of Asian new system. Japan claimed that, the future Asian community should not be confined to such a narrow system as ASEAN +3 , but should construct ASEAN $+3+3$ including Australia, New Zealand and India, even USA. Especially in the Security Cooperation area, Japan should promote its conversational cooperation of Security Cooperation with India and Austria, etc.. For example, in the "Japan-Australia Joint Declaration 
on Security Cooperation", the two parties advocated that they both had common strategic interests and security cooperation interests. By means of substantial cooperation and strategic conversation of foreign affairs, national defence and other sections, Japan, USA and Australia would intensify their cooperation. In one word, Japan believes that due to the historical and realistic reasons in the Asian and Pacific districts, values community can not be realized within a short period of time, and what's most hopeful is to establish a security cooperation institution similar to NATO in these districts. Hence, the first thing Japan should do is to cooperate with countries having common values and realize security areas' cooperation systematization.

\subsection{Intensifying of free diplomacy}

Japan affirmatively confirmed that the reinforcement of its relationships with NATO, Australia and India is unprecedented in Japanese history. However, on the issue of Korean nuclear weapons, there existed a disharmonious sound between Japan and USA. In order to claim its interests to USA effectively, Japan thought it was necessary to elevate its voice in international society. In 2007 when Abe visited Europe, he expressed his opposing attitude towards EU's elimination of weapon embargo to China and towards China's joining of G8. And he also expressed his independent opinion to EU on the hotspots in Asia and Pacific and on the globalization, etc. Japan thought that an independent viewpoint was helpful for Japan's entering the Security Council. On the other hand, Japanese people are concerned about American emphasis on cooperation with China, while America is also concerned about Japan's deviating and reinforcing its independent diplomacy. And what's more, Japan would get closer to the more and more growing-up China. Expansion of these two concerns may cause strategic misunderstandings of these two countries.

\section{Limitations}

Obvious limitations of Japan's values diplomacy involve the following three aspects:

\subsection{Japan's values concept not really implanted in Japanese strategic culture}

Although values diplomacy has obvious strategic meaning, yet it differs from European and American countries which regard values as just a concept but not national interests, and this difference has not been sufficiently focused on in Japan. Freedom, democracy and human rights were, after all, brought in from Occidental countries, and although they have been developed in Japan for nearly a century, they are not as much mature. For example, in the aspect of party system, the fact that the national party's general conservatism, and long-time one party in power has led international society to thinking there has been particularity in Japanese democratic system development. Furthermore, there has always been a tradition of "dependence" in Japanese strategic culture, because its values diplomacy obviously has a tendency to depending on American democracy. Therefore, international society suspects its life endurance.

\subsection{Implementation methods limiting effects of values diplomacy}

Methods of Japan implementing its values diplomacy are as follows: by means of ODA aid, to improves its status in those acceptance countries' diplomatic policies; through sending Peacekeeping force, to set up its image of being responsible; in virtue of academic and cultural exchanging, to develop its civilian diplomacy.

ODA aid is one of national strategies that have been long carried out by Japanese government. During its implementation of several decades, it indeed has played its part in improving Japan's international status. However, if Japan added values factors into aiding conditions, it would not be difficult to come to a conclusion that its image would be watered down. It would firstly think that this makes no difference from democratization proposed by Occidental countries in their aid. Hence, implementation of values diplomacy in this way might, on the contrary, do harm to its international image.

In terms of oversea army sending, such as in the issue of sending sea militia to Indian Ocean for supporting American army, Japanese parties were separated into two groups: one called "following America Party" headed with liberal and democratic Party and Civil Party, who thought that it was a key for Japan to denote to America that they would bear important responsibilities in international security area, and if this issue was not passed in Japanese national congress, it would greatly impair its international image; another group called "coordination Party" headed with Democratic Party, who thought that Japan's sending army had conflicted with its national constitution per se, and at the same time, they hadn't got UN's approval in sending peacekeeping force into Afghanistan, so they did not agree sending troops. Since Democratic Party accounted for the majority of seats in the senate, it was rather difficult for Japanese government trying to set up a responsible image by this means.

Academic and cultural exchange is a diplomatic method proposed by Junichiro Koizumi in his ruling period. However, a system of researching foreign countries in Japan has been rather fragile. For instance, in other countries, research institutes affiliated to famous universities or independent institutes are quite a lot, eg., American research centers, Asian research centers, and Japanese research centers, etc, while in Japan, there even have not been any single institute that conducts a comprehensive research on the present America, which confined Japan's exchange with global academy and culture. Furthermore, a large quantity of people in the world fancy Japanese tea ceremony, caricature and sumo, etc,. Yet those who really want to learn are highly less. Japan's cultural universality is not as what its government imagines. 


\subsection{Ideology leadership not recognized by international society}

Although Japanese government clarified that their values diplomacy was not aimed at any single country, and it was just a wide direction of Japan's continually developing its diplomacy. Yet it can not be denied that the essence of its values diplomacy is ideology, and it is quite probable that the "Freedom and Prosperity Arc" can cause antipathy of nations inside and outside the arc. Countries inside the arc are centered with China and Russia. While the latter thinks that the development of Japanese values diplomacy in Middle East and Europe has greatly impaired Russian interests in this area, the former holds the view that Japan's establishment of democratic network is aimed at blocking China. Meanwhile, China thinks that Japan's values diplomacy and strategic reciprocity exactly revealed the two sides of its attitude towards China, namely, competition and cooperation, holding down and coordination. These two policies supplement each other: they can trade off when necessary and they can also be respectively used on different occasions. In addition, among nations inside the arc, countries such as Africa and South America also hold veiled opinions this idea, thinking that Japan ignores their development.

In January 2008 when Fukuda made his speech in the $169^{\text {th }}$ national congress about administration policies, he expressed denoted that Japan would continue to make contributions to the world's democracy, peace and development. Masahiko Komura said in the 62th General Assembly "the way of freedom is indispensable to realize justified vote and democracy as well as peace. In order for democratization to be pushed forward, we will provide all necessary aids ...

Not in conflict with democracy, legal governing is foundation of peace and prosperity, and our country will provide aid for legal perfection of developing countries. Background of pushing forward the above causes is based on values concepts such as freedom, human rights, democratic and legal system, which are all international issues. Human nature's dignity is the most important foundation." He advocated their democratic values concept without restraint.

The new prime minister Tarou Asou Taro Aso had a speech in the 63th General Assembly, expressing his idea of building up Japan's reciprocity with China and South Korea, but at the same time, emphasizing that Japan would push forward global peace and development together with those countries having the same values. All this indicates that Tarou Asou Taro Aso has not totally changed his diplomatic concept. What China is most concerned is whether Japan's democratic network would include Taiwan. Taiwan is the fourth largest trade partner of Japan, and in 2006, people that exchanged visits between Japan and Taiwan rose to approximately 250 . They have kept in close contact with each other in each field. Although Japan claimed that it was a "passive country" in terms of Taiwan issue, authority negotiation of Mainland and Taiwan is the key of exploring a way to peacefully revolve issues. And they criticized that Japan's values diplomacy aiming at Taiwan Issue was incorrect. Making a comprehensive view of relationships of the Mainland and Taiwan nowadays, we think that the primary topic will transfer from Reigning and Independence to System. If Japan and Taiwan make an issue of freedom and democracy, China's unification might be greatly influenced.

\section{References}

Asahi news. October $8^{\text {th }}, 2007$.

Fukudahaku. (2006). To The Imparity Suffrage's Dispute Litigate. Public Opinion of Centrality, Vol.4.

Global Times. September $27^{\text {th }} 2008$.

Hosiyamaryu. The Diplomatic Aim is To Realize The New Integrated Security and Safeguard Stratagem of Japan. The General Country Identity.

IIPS. (2007). The Policy Research, November $11^{\text {th }}$, p331.

Richard J. Samuels. Securing Japan-Tokyo's Grand Strategy and the Future of East Asia.

Shinzo Abe. [Online] Available: http://www.mofa.go.jp/mofaj/press/enzetsu/19/eabe_0822.html.

Soetanihouhide. (2005). Middle-power Diplomatism of Japan ----Japan's Choice and Conceive in Postwar. Chikuma Publishing Company. p213.

Tarou Asou Taro Aso. (2007). Collection and Analysis of Intelligence, and Diplomacy of Developing and Publishing Opinions. In Liberty and Democracy, No.2, 70-71.

Tarou Asou Taro Aso. [Online] Available: http://www.mofa.go.jp/mofaj/press/enzetsu/17/easo_1207.html.

The Ministry of Foreign Affairs of Japan. (2007). Diplomatic Book.

The Ministry of Foreign Affairs of Japan. [Online] Available: http://www.mofa.go.jp/mofaj/area/china/yoron05/index.html.

The Ministry of Foreign Affairs of Japan. [Online] Available: http://www.mofa.go.jp/mofaj/area/australia/visit/0703_ks.html.

The Ministry of Foreign Affairs of Japan. [Online] Available: http://www.kantei.go.jp/jp/kakugikettei/2002/1128tf.html The Ministry of Foreign Affairs of Japan. (2008). Diplomatic Book. 